2014

\title{
The Artificial Medium Laws Theory
}

Nachshon Goltz

Follow this and additional works at: http:// digitalcommons.osgoode.yorku.ca/olsrps

\section{Recommended Citation}

Goltz, Nachshon, "The Artificial Medium Laws Theory" (2014). Osgoode Legal Studies Research Paper Series. 51.

http://digitalcommons.osgoode.yorku.ca/olsrps/51 


\section{OSGOODE HALL LAW SCHOOL LEGAL STUDIES RESEARCH PAPER SERIES}

Research Paper No. 47

Vol. 10/ Issue. 11/ (2014)

\section{The Artificial Medium Laws Theory}

Nachshon Goltz

\section{Editors:}

Editor-in-Chief: Carys J. Craig (Associate Dean of Research \& Institutional Relations and Associate Professor, Osgoode Hall Law School, York University, Toronto)

Production Editor: James Singh (Osgoode Hall Law School, York University, Toronto)

This paper can be downloaded free of charge from:

http://ssrn.com/abstract=2429899

Further Information and a collection of publications about Osgoode Hall Law School Legal Studies Research Paper Series can be found at:

http://papers.ssrn.com/sol3/JELJOUR_Results.cfm?form_name=journalbrowse\&journal_id=722488 
Osgoode Legal Studies Research Paper No. 47

Vol. 10/ Issue. 11/ (2014)

\title{
The Artificial Medium Laws Theory
}

\author{
Nachshon Goltz
}

\begin{abstract}
: implications.

\section{Keywords:}

Media, Laws

Author(s):

Nachshon Goltz

Osgoode Hall Law School

York University, Toronto

E:n.goltz@gmail.com
\end{abstract}

This paper articulates the Artificial Medium Laws Theory. The theory is comprised of Perceived Psychological Dimensions, namely: sound, picture, moving picture, time and interaction. These dimensions are the building blocks of the theory's five laws: 1) The Truth in the Medium is Context Dependent, 2) The Stronger Dimension Prevails, 3) Medium with Time Dimension Determines its Usage Length, 4) The More Dimensions the Medium Poses the Weaker the User's Imagination, and 5) The User is Bound to All the Laws. The theory seeks to explain the artificial medium influence on human users and to suggest potential 


\title{
Nachshon Goltz \\ York University
}

\section{The Artificial Medium Laws Theory}

\begin{abstract}
This paper articulate The Artificial Medium Laws Theory. The theory is comprised of Perceived Psychological Dimensions, namely: sound, picture, moving picture, time and interaction. These dimensions are the building blocks of the theory's five laws: 1) The Truth in the Medium is Context Dependent, 2) The Stronger Dimension Prevails, 3) Medium with Time Dimension Determines its Usage Length, 4) The More Dimensions the Medium Poses the Weaker the User's Imagination, and 5) The User is Bound to All the Laws. The theory seeks to explain the artificial medium influence on human users and to suggest potential implications.
\end{abstract}

\section{Introduction}

Twenty years ago, I conducted an unplanned self-experiment, avoiding any media for a year, except for listening to the radio intensively. After this year, I watched cable TV almost 24 hours a day, for a week. When the experiment ended, the laws was created in my mind and written on a piece of paper. Since then, I tried to explain the theory and find examples that will make it understandable to others. My purpose in this article, to use McLuhan words, is, "to invite criticism, directed not at me or at my rhetoric, but rather at the substance and contents of my thoughts" (1975:74). 
The Artificial Medium Laws Theory is grounded in the literature of 'medium theorists', to use Meyrowitz (1985) term. This term is a variant of the more common and widespread media ecology, which Meyrowitz studied, but renamed the term in his writing. The 'media ecologists' do not suggest that the means of communication wholly shape culture and personality, rather that changes in communication patterns are one very important contributant to social change and one that has generally been overlooked (Meyrowitz, 1985:18). Put simply, the medium theorists are arguing that the form in which people communicate has an impact beyond the choice of specific messages.

Marshall McLuhan, the leading medium theorist, describes media as extensions of the senses and claims that the introduction of a new medium to a culture, therefore, changes the "sensory balance" of the people in that culture and alters their consciousness (McLuhan and Zingrone, 1995:234). However, according to Meirowitz (1985:22), "the greatest problem with the medium ecologists is that ultimately they provide more of a perspective for studying the effects of media on behavior than they present a detailed theory. The insights, observations, and evidence they collect point to the need to study media environments in addition to studying media messages, but they do not form a clear set of propositions to explain the means through which media reshape specific behaviors". An example to the said criticism is McLuhans' (1988) laws of the media.

McLuhans' four laws are framed as questions: (1) "What does the artefact enhance or intensify or make possible or accelerate?; (2) If some aspect of a situation is enlarged or enhanced, simultaneously the old condition or unenhanced situation is displaced hereby. What is pushed aside or obsolesced by the new 'organ'?; (3) What recurrence or retrieval of earlier actions and services is brought into play simultaneously by the new form? What older, previously obsolesced ground is brought back and inheres in the new form?; and (4) When pushed to the limits of its potential (another complementary action), the new form will tend to reverse what had been its original characteristics. What is the reversal potential of the new form?" (1985:99). An attempt to interoperate this laws in the context of the artificial medium laws theory is beyond the scope of this paper. 
The artificial medium laws theory concurs with medium ecologist that see the hazards of new media, by arguing that the advancement of artificial mediums are posing hazards to humans. However, the theory is trying to avoid the criticism mentioned above on the lack of 'empiricism' in medium theory, by presenting a linear, logical and empirical supported defined laws that should be easily applicable and produce clear insights and understanding of the artificial medium and its effects.

Artificial medium is defined as a men made device that mediate reality to our senses and perception. Television, Radio, Newspaper with pictures, films, the internet, cell phones, virtual reality and similar mediums are few examples. These artificial mediums were also referred to as advanced technologies, electronic media and other names. A book with no pictures is not considered an artificial medium for it does not mediate reality through our senses but rather convey ideas through our understanding of words and language, completely open to our interpretation. The term 'Artificial Medium' is used, and not media, to suggest that further development of the theory is applicable to 'non-artificial medium', i.e. humans.

The theory includes two components: the perceived psychological dimensions and the five artificial medium laws. The theory should be treated as a whole, working as a framework for understanding artificial mediums and as a method to draw insights regarding the future of artificial mediums influence on humans and society.

The laws and the perceived dimensions they refer to are intertwined: each artificial medium poses one or more perceived psychological dimensions: picture (newspaper), sound (radio), sound and moving picture (TV), sound, moving picture and time (Internet) and sound, moving picture, time and interaction (virtual worlds). These dimensions have hierarchical order, from the weakest (picture) to the strongest (interaction). For example, user exposure to low level dimension (the sound of the radio) will be less influential than the user exposure to silent movie (moving picture as a higher level dimension).

The picture, sound and moving picture dimensions are simple and are received in a direct way through our senses, the eyes and the ears. However, the time and interaction dimensions are 
much more complex and are not a direct experience of the eyes or the ears. A thorough discussion of the perceived psychological dimensions is beyond the scope of this article. Nonetheless, a basic description of the time and interaction dimensions are needed.

The article will first provide a basic description of the time and the interaction dimensions. Further, the article will explain each law and demonstrate its existence through examples. The first law, 'The Truth in the Medium is Context Dependent', argues that it is the context (news, comedy website etc.) that define the credibility of the message and that the more dimension the medium possess, defining the context becomes more difficult. This will be illustrated through two examples of false news stories that started at a satiric website and ended up treated as solid news stories.

The second law, 'The Stronger Dimension Prevails', argues that given the hierarchy of the perceived psychological dimensions, a combination of low level dimension (voice) with high level dimension (interaction) will result in supremacy of the higher dimension in its influence om the user. It is further argued that there is a complex interaction system within the dimensions that could bring to powerful results. This law will be illustrated through the You Tube video KONY 2012, arguing that while the sound dimension described Joseph Kony war crimes in Uganda, the visual tell a different story about the power of social media. It is suggested that this combination brought to the amazing 99 million views.

The third law, 'Medium with Time Dimension Determines its Usage Length', argues that the more the medium possess dimensions, the determination of usage time is shifting from the user to the medium. This law will be illustrated through the correlation between internet addiction and usage time. Moreover, it will be demonstrated that this correlation is even more alarming when measured in a stronger medium, virtual worlds.

The fourth law, 'The More Dimensions the Medium Poses the Weaker the User's Imagination', will be illustrated through the research done on creative imagination and television arguing that mediums that possess more dimensions than TV, i.e., the internet and virtual worlds, 
brings to the extension of the visualization Hypothesis further, from the senses, vision and sound into time and interaction, living little space, if any, for the users' imagination.

The fifth and last law, 'The User is Bound to All the Laws', will argue that the user of the artificial medium is inherently bound to all the laws. Furthermore, where the user is involved in creating the content, the laws influence is even stronger. This will be illustrated by the high rate of suicide among reality TV participants suggesting that the urge to bridge the gap between the real and the virtual is taking its toll.

\section{The Time Dimension}

Mumford (1934) shows how, beginning in the fourteenth century, the clock made us into timekeepers, and then time-savers, and now time-servers. In the process, we have learned irreverence toward the sun and the seasons, for in a world made up of seconds and minutes, the authority of nature is superseded, "Abstract time became the new medium of existence" (17).

Innis (1950) divided media into time-binding and space-binding types. Time-binding media are durable. They include clay or stone tablets. Space-binding media are more ephemeral. They include modern media such as radio, television, and mass circulation newspapers. He argued that media 'biases' toward time or space affected the complex interrelationships needed to sustain an empire.

Building on Innis's work, Strate (2011) argue that while, “oral cultures looked to the past and literal cultures have the potential to turn around and look towards the future, our electronic culture seems to be fixated in the present" (2011a). We are repeatedly being told: "live the moment' and are 'losing distinction between sacred and profane time, losing the distinction between night and day".

The psychologist Robert Ornstein (1970) pointed out in his classic book 'On the Experience of Time', that the perception of time is a cognitive process and is therefore subject to 
cognitive illusion (Orenstein, 1970). In general, the more cognitive processing you do within a given period, the more time you judge to have passed.

From a biological point of view, while every cell of the human body contains a simple clock, the master internal clock is located in the suprachiasmatic nucleus (SCN) (Klein et al., 1991), a small cluster of about ten thousand brain cells located at the base of the brain. The primary role of the SCN is to control our internal circadian rhythms. Over fifty circadian rhythms - including those of blood pressure, digestive enzymes, fertility cycles, mood, and sleep/wake cycles - are regulated by the SCN (Kryger et al., 2005). Natural environmental cues - or zeitgebers (literally, "time givers" in German) - reset our internal clock each day so that our bodily processes continue to be in harmony with the world around us.

For people and animals, light is the most important zeitgeber. Light passes directly through our eyes and is carried to the SCN by the optic nerves. Once it reaches the SCN, light resets the internal clock and, among other functions, inhibits the production of a hormone called melatonin, which makes you sleepy when it gets dark, making you tired, and go to sleep. The Internet, TV, TiVo, twenty-four-hour stores, international travel, and ordinary hundred-watt light bulbs constantly push and pull at the hands of your internal body clock (Zimbardo \& Boyd, 2008:193).

\section{The Interaction Dimension}

Interaction between people is defined as follow: "interaction take place in the moment when actions of two people or more are observed as dependent one in the other, mutually" (Starkey, 1989:325). Meaning, "It can be said that interaction are working when every one of at least two participants is aware of the presence of the other, and each one have a reason to believe that the other is aware in the same level", and in this way happens the creation of, "state of mutual awareness". 
A relatively simple model of interaction level regarding information technologies enabling interaction in one dimension (Rogers, 1986), define the interaction level as, "the ability of new communication systems (usually including computer as one element) to 'talk back' to the user, almost like a person participating in a conversation. The level of interaction is a variable; according to this model, some information technologies are relatively low in their interaction level (Cable TV for example), while other (like online bulletin boards) are higher in their interaction level". Based on this definition, a hierarchy of interaction level of some selected information technology is being formed (Rogers, 1986:34):

Figwre 2. E. M. Rogers' 1-dimensional Scale of "Selected Communication Technologies an an Interactivity Continurm" (1987:34)

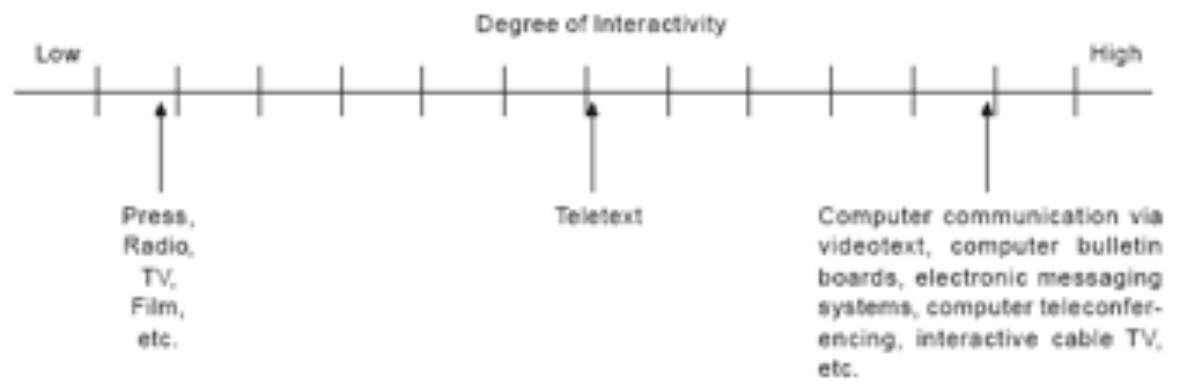

A more complex model of interaction in two dimensions (Steuer, 1995) is based on a matrix containing two variables: 'vividness' - defined as "the ability of technology to supply reach sensory mediated environment"; and 'Interactivity' - defined as "the degree in which technology users can affect the shape and content of the mediated environment". 
Figure 4. J. Siewer's (1995: 32) Clessification of Variows Media Techmologies Csing the Dimensions 'Tividness' and 'Juteracrivin'

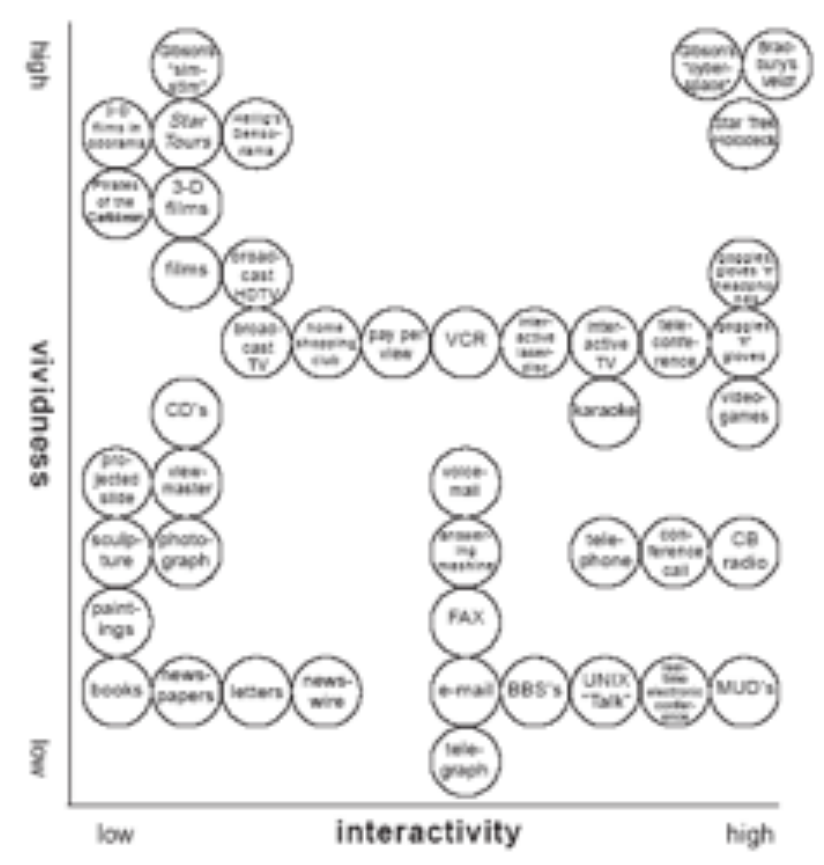

While in the internet exist a level of interactivity expressed in chat rooms and other online services, the assumption is that in virtual worlds the level of interactivity increases in two ways: firstly, since the user being embodied by an avatar, the embodiment itself is being added to the interaction as well as characteristics like body language (of the avatar) that do not exist in other online application; secondly, in some virtual worlds the user can create items and even virtual environment as he wish and by that to interact with the virtual world itself.

\section{The Laws}

The theory contains 5 laws. While the first law relates to any artificial medium, the second can be applied only to artificial medium that have more than one dimension (Radio excluded, for example), the third is relevant only to artificial medium that have time dimension (television excluded). The fourth and fifth laws are relevant to any artificial medium, however, predict the 
most striking results with the most advanced artificial mediums, i.e., the ones that possess the most dimensions with the best quality.

\section{Law 1 - The Truth in the Medium is Context Dependent}

The only indicator the user has in order to find out if the information he or she is perceiving from the medium is true or false, is whether he is receiving the information from a comedy web site, for example (than most chances that the information is false) or from a news web site (that will allegedly have credibility).

In his book, 'Amusing Ourselves to Death,' Postman argues that, "[T]he concept of truth is intimately linked to the biases of forms of expression. Truth does not, and never has, come unadorned. It must appear in its proper clothing or it is not acknowledged, which is a way of saying that the "truth" is a kind of cultural prejudice" (1986:22). Furthermore, according to Postman, "Truth, like time itself, is a product of a conversation man has with himself about and through the techniques of communication he has invented" (24).

Wartella et al. (2003) argue that the frame for a message includes knowledge of its point, topic, and relevant background information; it provides the context for interpreting communication. As Goffman (1974) and others have pointed out, the impact of experience is a function of how that experience is interpreted, or framed. A classic demonstration was provided by Bransford and McCarrell (1974), who showed that what people learned from narratives depended on the frame they were given. Wartella et al. (2003:472) concludes that, "The general rule for communication theory, then, is that the effects of communication content are mediated by the frames people use in processing that content".

Moreover, as described by McAllister (2003) in 'Selling Survivor, The Use of TV News to Promote Commercial Entertainment", identifying and determining the context become more and more problematic. In his article, 'What is the difference between The Hobbit and the news? Not as much as there should be', Brooker (2012) is wondering, "News reports are looking more 
like movies - and movies are looking more like news reports. How are we supposed to tell them apart?". He gives the example of reports that an audience of cult movie buffs reacted badly to test footage from Peter Jackson's forthcoming Hobbit movie (Child, 2012). "The Hobbit is shot at 48 frames per second - twice as many frames as standard films. The studio claims this gives it an unparalleled fluidity. The viewers complained it was too smooth - like raw video. Some said it looked like daytime TV. What they meant, I guess, is that it seemed too "real", and therefore inherently underwhelming.".

Two examples of the said confusion are the story about North Korea Kim Jong-Un having his uncle eaten by 120 wild dogs that may have started in a satirical tweet and ended up in NBC news, Fox news and other news networks and websites (Taylor, 2014); and Sweden's justice minister posting a spoof article about marijuana-linked deaths on her Facebook page along with comments about her zero-tolerance against drugs (Associated Press, 2014).

\section{Law 2 - The Stronger Dimension Prevails}

It is assumed that the moving picture message in TV will be more dominant than a contradicting message conveyed in the sound. If the user will watch a relaxing nature film however the sound will portray horror movie, it is expected that the user will tend to rate his experience as more relaxing in contradiction to the user report in case that the message will be switched between the dimensions and the sound will be relaxing while the moving picture will be terrifying. According to the Theory, in the former situation it is expected that the user experience will be much less relaxing.

Moreover, it is suggested that there are complex mechanisms according to which it is possible to create a desired unconscious affect in the user perception by deliberately combining different messages in different perceived psychological dimensions received by the user at the same time. A simple example for this manipulative use of parallel dimensions can be seen in certain TV shows (Jerry Springer etc.) in which illustration videos are shown in black and white 
to enhance the sound affect. During these videos, certain objects are appearing in color to emphasis it and create 'breaks' in the sound dominance, in favor of moving picture.

More advanced example can be seen in the 'KONY 2012' phenomena. While the video narrator is talking about Joseph Kony, the war criminal and the activities to stop him, the moving picture is telling a completely different story, the story of social media and its power to change the world. The theory suggests that this powerful combination brought this movie to be watched by almost 100 million people worldwide.

\section{Law 3 - Medium with Time Dimension Determines its Usage Length}

Like other forms of addiction, Internet addiction consumes the addict's time and energy, harms his personal relationships, restricts his academic, professional and social potential (Kandell, 1998; Eppright et al., 1999) and may result in physical problems stemming from self-negligence (lack of sleep, little exercise, malnutrition and more) (Young, 1997). Researchers have found that $90-95 \%$ of self-defined Internet addicts reported mild to severe distress at work, in school, and in financial matters (Young, 1996a).

Internet addiction is a cross-culture syndrome and the amount of time the user spends online is its best predictor. A number of studies indicate a significant correlation between the amount of time spent surfing the Internet and the risk of developing Internet addiction amongst American college students, Chinese, Taiwanese, Internet users from Pakistan, and Australian students (Brenner, 1997; Liang, 2003; Lin \& Tsai, 2002; Suhail \& Bargees, 2006; Wang, 2001). However, the results found in a study of Italian Internet users did not support this assumption (Giovanni, 2007).

A number of studies have tracked the frequency of Internet addiction. In a study of 1,078 college students, it was found that $9.8 \%$ of the subjects possessed characteristics consistent with Internet addiction diagnoses (Armstrong et al., 2000). Similar results were found in a study of 576 students, revealing a 9.26\% addiction rate (Kubey et al., 2001). However, a conservative 
research study conducted using double diagnoses characteristics (Diagnostic Questionnaire - DQ and Internet Related Addictive Behavior Inventory - IARBI), found a $6 \%$ addiction rate (Brenner, 1997). These results were further reinforced by the result of a US nationwide survey of 17,251 Internet users visiting abcnews.com, which indicated a 6\% addiction rate (Greenfield, 1999).

While many negative side effects result from Internet addiction, it seems that addiction to virtual worlds, stronger artificial medium, is a far more serious problem. Research conducted of 3,989 users of the virtual world Everquest.com indicated that $15.4 \%$ of the subjects reported experiencing symptoms of withdrawal when not able to use the virtual world, $23.8 \%$ experienced mood modification while using the virtual world, $28.8 \%$ used the virtual world even when they did not enjoy the experience, and 18.4\% reported problems in academics, health, finances or relationships (Yee, 2002). A follow-up survey of 2,237 MMORPG users concluded that 40.7\% of the subjects considered themselves addicted to the game experience (Yee, 2004).

There are several documented deaths as a result of fatigue due to extended and continuous use of virtual worlds. Li Syong Saup of South Korea died after using the virtual world Starcraft.com for more than 50 hours continuously (Naughton, 2005). Kso Yan of China died after using virtual worlds for more than 15 days continuously, during the New Year holiday (Williams, 2007). Another Chinese individual died after using virtual worlds for 3 days straight (Thomson, 2007).

$\mathrm{Hu}$ Bin, a 16-year-old Chinese teenager from the province Anhuvi at Lujiang County died two days after he swallowed an insecticide he brought with him to the Internet bar (Ying et al. 2006). Before $\mathrm{Hu}$ committed suicide he used virtual worlds at the Internet bar for 11 days straight. According to reports, the words "even the gods cannot save me," were written on the family door. Hu's father said that when Hu was about to die, He said: "I drank it [the pesticide] because I wanted to make sure that you could not save me. I have played enough.".

3-month-old Sa-rand ("love" in Korean) died as a result of her parents neglecting her in order to raise a virtual baby in a virtual world (Sang-Hun, 2010); a 22-year-old arrested for 
clubbing his 53 year-old mother to death after she criticized his online gaming habit (AFP, 2010). And finally, The 23 Taiwanese Chen Rong-yu lied dead in internet café for 9 hours before anyone notice it. He was playing virtual game for 23 hours in a row (Rob, 2012).

\section{Law 4 - The More Dimensions the Medium Poses the Weaker the User's Imagination}

Most, if not all of the empirical research regarding media and imagination was conducted during the 80's and focused on television. For several reasons, undoubtedly the problem of quantifying the imagination being one of them, this line of research had not been pursued further to other, more advanced artificial mediums. Therefore, the existing research in this field will be introduced and conclusions to the present and future will be drawn.

Two competing theories have been introduced regarding the effects of TV use on the creative imagination (Valkenburg \& van der Voort, 1994): Stimulation Theory - TV stimulates creative imagination through its content; Reduction Theory - TV hinders the development of creative imagination. While five types of reduction hypotheses have been proposed in the literature: passivity, displacement, rapid pacing and arousal (Salomon, 1984; Singer el al., 1984), only the Visualization hypothesis is relevant in the context discussed here.

In the visualization hypothesis view, the visual nature of TV is held responsible for TV's reductive effect on the creative imagination. Unlike verbal media as radio and print, TV presents the viewer with ready-made visual images and thus leaves little room for forming one's own images. When engaged in creative thinking, it is hard to dissociate oneself from the images supplied by TV, with the result that one has difficulty generating novel ideas (Greenfield \& Beagles-Ross, 1988; Meline, 1976; Webb, 1980).

The studies reviewed by Valkenberg \& van der Voort (1994) illustrate the visualization hypothesis by indicating that children who watched a TV story, more often used visual content as a basis for drawing story related inferences, whereas children who had heard the radio story more often based their inferences on the verbal content and on information from outside of the story, 
such as personal experience (Beagles-Ross \& Gat, 1983; Meringoff, 1980; Vibbert \& Meringoff, 1981).

Further support to the visualization hypothesis was provided by Conway and Siegelman (1978:191) arguing that "Heavy viewing destroy the natural ability of children to form mental images from what they hear or read. With too much TV, the young child's basic capacity of imagination, like an unused muscle, never reaches a level adequate for performing even the most elementary of creative acts".

Mander (1978:216), addressing the same hypothesis argued that: "More than any other single effect, television places images in our brain. It is melancholy fact that most of us give little importance to this implantation, perhaps because we have lost touch with our own imagecreating abilities, how we use them and the critical functions they serve in our lives".

Goldberg (1994:16) commentated on the images created by TV, stating that in contrary to radio and print media in which we create our own images, "[TV] supplies the same image to millions of people at the same time. We process those images rather than create them".

Latham (2003:11) support this line of thinking, "with images that are processed through the sensory system, rather than created in the mind's eye, we take in what Giegerich $(1985: 17)$ refers to as a 'distillation of image'...In the case of young children, neuronal pathways are being wired and shed according to their use patterns. When concentrated representational electronic images are observed through the visual sensory system, other body and sense modalities consequently receive less stimulation".

Pearce (1992:166) argues that, "Television feeds both stimulus and response into that infant-child brain, as a single paired-effect, and therein lays the danger. Television floods the brain with a counterfeit of the response the brain is supposed to learn to make to the stimuli of words or music. As a result, much structural coupling between mind and environment is eliminated; few metaphoric images develop; few higher cortical areas of the brain are called into 
play; few, if any, symbolic structures develop". Therefore, "failing to develop imagery means having no imagination".

In her research on video game users and dreams, Gackenbach et al. (2010) found that high end users where associated with lucid dream type (Gackenbach, 2006, 2009), had more dead and imaginary characters in their dreams (Gackenbach et al., 2009), and were coded as containing more incongruent and vague elements than were those of low-end gamers (Gackenbach et al., 2009a).

In contrast to Gackenbach et al. assumption that dream bizarreness in high end video game users is a result of developed creative imagination, the theory will argue that these finding emphasis the deep influence of video games (and consequently, virtual worlds) on the user and support further the Visualization Hypothesis. It can be said that the fact that the most 'sacred' place of the imagination - dreaming - has been 'invaded' by the artificial medium, is a warning sign regarding its deep and embracing influence.

Support to this argument can be found in the results of a study conducted among users of the virtual world "Everquest" (Smahel et al, 2007), according to which 80.6\% of the women and $58.4 \%$ of the men players reported dreaming of the virtual world or having a dream taking place in the virtual world environment.

Virtual worlds brings to the extension of the visualization Hypothesis further, from the senses - vision and sound - to the perceived psychological dimensions, weak and almost irrelevant in TV, stronger in video games and dominant and supreme in virtual worlds. It is no longer the visual that is replacing the images that could have been created by the imagination, but also the time and interaction that are projected and consumed from the artificial medium and are replacing the natural pace and creation of these dimensions within the person. The most internal object, the mind, is becoming external nourishing falsely from the artificial medium perceived psychological dimensions, living little space, if any, for the imagination. 


\section{Law 5 - The User is Bound to All the Laws}

This law applies to users that are using the medium actively. In its simple form the actor in a movie is using the medium while the viewer is passive. An example to the user-actor subordination to the medium laws would be male and female actors that are playing a loving couple in the movie and ends up being a couple in reality. Another example would be the melt down of KONY2012 director as a result of abusing the medium laws (even if unintentionally) as described earlier (Daily Mail, 2012).

The same phenomenon is happening on the internet and virtual worlds when most of the users are active. The law is forecasting that under these circumstances, the laws impact would be more intense and the line between the virtual and real will be completely blurred.

An illustration can be found in veteran New York journalist Seth Kaufman (2013) findings. Kaufman has explored the suicide rate of US reality shows and compared it to the nation average suicide rate. Kaufman's determined the number of contestants on U.S. reality shows since 2005 totals 34,080, 14 of them suicides. The national average rate for suicides is 12.4 per 100,000 people, according to the American Foundation for Suicide Prevention. Therefore, the suicide rate among US reality show participants is more than three times the national average.

The theory suggests that the gap between the real and the virtual, and the natural urge to bridge it, are causing these dramatic results.

\section{Conclusion}

As one editor commented, proving the theory is a lifelong research agenda. It is my hope that empirical research, designed to examine the theory assumptions - the perceived psychological dimensions and the laws, will be carried. This further research will enable deeper understanding 
of the theory and its implications as well as means to protect users from its suggested undesired effects.

\section{Reference}

AFP (2010), 'S. Korean Jailed for Killing mother Over Gaming Addiction', (July 2, 2010), http:// www.google.com.hostednews/afp/article/ALeqM5iSGEydod6Z_YdAeX5n3bu7BKO47Q

Armstrong, Lynette et al. (2000), Potential Determinants of Heavier Internet Usage, 53 Int'1 Journal of Human-Computer Studies 537.

Associated Press (2014), Sweden's justice chief left high and dry over spoof marijuana deaths story, theguardian.com, (7 January 2014), http://www.theguardian.com/world/2014/jan/07/ sweden-justice-minister-spoof-marijuana-deaths-story

Beagles-Ross, J., \& Gat, I. (1983), 'Specific Impact Of Radio And Television On Children's Story Comprehension', 75 Journal of Educational Psychology, pp. 128-137.

Bransford, J. D., and McCarrell, N. S., (1974), A Sketch of Cognitive Approach to comprehension. In W. B. Weimer and D. S. Palermo (eds.), Cognition and the Symbolic Processes. Hillsdale, NJ: Lawrence Erlbaum, pp. 299-303.

Brenner, V. (1997), 'Psychology of Computer Use: Parameters of Internet Use, Abuse, and Addiction: The First 90 Days of the Internet Usage Survey', 80 Psychology Rep. 879.

Brooker, Charlie (2012), 'What is the difference between The Hobbit and the news? Not as much as there should be', guardian.co.uk, (29 April 2012), At http:/www.guardian.co.uk/ commentisfree/2012/apr/29/difference-hobbit-news-not-much

Child, Ben (2012), 'The Hobbit: first glimpse gets mixed response', guardian.co.uk, (25 April 2012), http://www.guardian.co.uk/film/2012/apr/25/the-hobbit-first-screening-cinemacon? newsfeed $=$ true 
Conway, Flo \& Siegelman, Jim (1978), Snapping, Philadelphia, PA: J. B. Lippincott.

Copper, Rob (2012), 'Gamer lies dead in internet café for 9 hours before anyone notices', dailymail.co.uk, (Feb 3, 2012), http://www.dailymail.co.uk/news/article-2096128/Gamer-liesdead-Taiwan-internet-cafe-9-HOURS-notices.html

Daily Mail (2012), 'You're the devil, you're the devil': New footage of Kony video director emerges 'ranting at traffic while naked on busy street', (19 March 2012), http:// www.dailymail.co.uk/news/article-2116981/Jason-Russell-arrested-New-footage-Kony-2012video-director-ranting-naked-emerges.html

Eppright, T. et al. (1999), 'Internet Addiction: A New Type of Addiction', 96 Missouri Medicine 133.

Gackenbach, Jyne, Kuruvilla, Beena, \& Raelyne Dopko (2009a), 'Video Game Play and Dream Bizarreness', 4 Dreaming, pp. 218-231.

, Kuruvilla, B., Dopko, R., \& Le, H. (2010), 'Dreams And Video Game Play', In F. Columbus (Ed.), Computer Games: Learning Objectives Cognitive Performance And Effects On Development, Hauppauge, NY: Nova Science, Ch. 5.

(2006), 'Video Game Play And Lucid Dreams: Implications For The Development Of Consciousness', 16 Dreaming, pp. 96-110.

(2009), 'Electronic Media And Lucid-Control Dreams: Morning After Reports', 19

Dreaming, pp. 1-6.

, Matty, I., Kuruvilla, B., Samaha, A. N., Zederayko, A., Olischefski, J., \& Von Stackelberg, H. (2009), 'Video Game Play: Waking And Dreaming Consciousness', In Krippner, S. (Ed.), Perchance To Dream, Hauppauge, NY: Nova Science, pp. 239-253.

Giovanni, Ferraro (2007), Internet Addiction Disorder: An Italian Study, 10 Cyberpsychology \& Behavior 170. 
Goffman, E. (1974), Frame Analysis: An Essay on the Organization of Experience, New York, NY: Harper \& Row.

Goldberg, Debra Ann (1994), 'Television From Jungian Perspective', Psychological Perspectives, 29:2, pp. 10-20.

Greenfield, P. M., \& Beagles-Ross, J. (1988), 'Radio vs. Television: Their Cognitive Impact On Children Of Different Socioeconomic And Ethnic Groups', Journal of Communication, 38:2, pp. 71-92.

(1999), 'Psychological Characteristics of Compulsive Internet Use: A Preliminary Analysis, 2 Cyberpsychology \& Behavior 403.

Innis, Harold (1950), Empire and Communications, London, UK: Oxford University Press.

Kandell, J.J. (1998), 'Internet Addiction on Campus: The Vulnerability of College Students', 1 Cyberpsychology \& Behavior 11.

Kaufman, Seth (2013), 'Suicide Rate for Reality Contestants Three Times the National Average', TheKingofPain.com, (April 1, 2013), http://www.thekingofpainbook.com/2013/04/01/tkopexclusive-suicide-rate-for-reality-contestants-three-times-the-national-average/

Klein, D., Moore, R., and Reppert, S. (1991), Suparchiasmatic Nucleus: The Mind's Clock, New York: Oxford University Press.

KONY2012, Wikipedia.org, http://en.wikipedia.org/wiki/Kony_2012

Kryger, M., Roth, T., and Dement, W.C. (2005), Principles and Practice of Sleep Medicine, Philadelphia, PA: Saunders.

Kubey, Robert W. et al. (2001), 'Internet Use and Collegiate Academic Performance Decrements: Early Findings', 51 Journal of Communication 366. 
Latham, Christopher Lawrence (2003), High Tech Image Influences On Development Of Young Children's Imaginative World Making, Dissertation Abstracts International: Section B: The Sciences and Engineering Vol. 63(7-B), 2003, pp. 3495 [ProQuest].

Liang, Guo, (2005), 'Surveying Internet Usage and Impact in Twelve Chinese Cities', 'Surveying Internet Usage and Impact in Twelve Chinese Cities', http://news.bbc.co.uk/2/shared/bsp/hi/pdfs/ 10_02_06_china.pdf

Lin, Sunny S.J. \& Tsai, Chin-Chung (2002), 'Sensation Seeking and Internet Dependence of Taiwanese High School Adolescents', 18 Computers In Human Behavior 411.

Mander, J. (1978), Four Arguments For The Elimination of Television, New York, NY: Perennial.

McAllister, M. (2003), 'Selling Survivor, The Use of TV News to Promote Commercial Entertainment", pp. 209-226 in Valdivia, Angharad, N., (ed.), A Companion to Media Studies, Oxford, UK: Blackwell.

McLuhan, Eric and Zingrone, Frank (ed.) (1995), Essential McLuhan, Concord, On: Basic Books.

McLuhan, Marshall (1975), 'McLuhan's Laws of the Media', Technology and Culture, 16:1, pp. 74-78.

, and McLuhan, Eric (1988), Laws of media : the new science, Toronto, On: University of Toronto Press.

Meline, C. W. (1976), 'Does The Medium Matter?', Journal of Communication, 26:3, pp. 81-89.

Meringoff, L. K. (1980), 'Influence Of The Medium On Children's Story Apprehension', 72 Journal of Educational Psychology, pp. 240-249.

Meyrowitz, Joshua (1985), No Sense of Place, The Impact of Electronic Media on Social Behavior, New York, NY: Oxford Uni. Press. 
Mumford, Lewis (1934), Technics and Civilization, Chicago, IL: University of Chicago Press.

Naughton, Philippe (2005), 'Korean Drops Dead After 50-hour Gaming Marathon', London Times, (Aug. 10, 2005), http://www.timesonline.co.uk/tol/news/world/article553840.ece;

Ornstein, R. E. (1970), On the Experience of Time, Baltimore, MD: Penguin Books.

Pearce, J. (1992), Evolution's End: Claiming The Potential Of Our Intelligence, San Francisco, CA: Harper Collins.

Postman, Neil (1986), Amusing Ourselves to Death, New York, NY: Penguin Books.

Rogers, Everett M. (1986), Communication technology, The New Media In Society. New York, NY: Free Press.

Salomon, G. (1984), "Television Is "Easy" And Print Is "Tough": The Differential Investment Of Mental Effort As A Function Of Perceptions And Attributions', 76 Journal of Educational Psychology, pp. 647-658.

Sang-Hun, Choe (2010), 'South Korea Expends Aid for Internet Addiction', N.Y. Times, (May 28, 2010), at A4, http://www.nytimes.com/2010/05/29/world/asia/29game.html.

Singer, J.L., Singer D.G., and Rapaczynski, W. (1984), 'Children's Imagination As Predicted By Family Patterns And Television Viewing: A Longitudinal Study', 110 Genetic Psychology Monographs, pp. 43-69

Smahel, David et al. (2007), 'MMORPG Playing of Youths and Adolescents: Addiction and its Factors', Vancouver: Association of Internet Researchers, Interner research 8.0: let's play (2007), http://www.muni.cz/research/publications/726643.

Starkey, Duncan (1989), 'Interaction, face-to-face', in International Encyclopedia of Communications, New York, NY: Oxford University Press, pp. 325-7. 
Steuer, Jonathan (1995), 'Defining Virtual Reality: Dimensions Determining Telepresence', In Communication In The Age Of Virtual Reality (Franck Biocca \& Mark R. Levy, eds.), Hillsdale, NJ: Lawrence Erlbaum.

Strate, Lance (2011a) A public lecture given at Grand Valley State University, Grand Rapids, Michigan, on September 21, 2011, YouTube.com, http:/www.youtube.com/watch? $\mathrm{v}=24$ oaWPApedE

, On the Binding Biases of Time and Other Essays on General Semantics and Media Ecology (2011)

Suhail, Kausar \& Bargees, Zobia (2006), 'Effects of Excessive Internet Use on Undergraduate Students in Pakistan', 9 Cyberpsychology \& Behavior 297.

Taylor, Adam (2014), 'The Story About Kim Jong-Un Having His Uncle Eaten by 120 Wild Dogs May Have Started with a Satirical Tweet', BusinessInsider.com, (Jan 5, 2014), http:// www.businessinsider.com/jang-song-taeks-execution-rumors-2014-1

Thomson, Ian (2007), 'Chinese Gamer Dies After Three-Day Session', VNUNet.com (Sep. 17, 2007), http://www.vnunet.com/vnunet/news/2198850/chinese-man-dies-three-days.

Valkenburg, Patti M. and van der Voort, Tom H. A. (1994), 'Influence of TV on daydreaming and creative imagination: A review of research', Psychological Bulletin, 116:2, pp. 316-339.

Vibbert, M. M., \& Meringoff, L. K. (1981), 'Children's Production And Application Of Story Imagery: A Cross-Medium Investigation' (Tech. Rep. No. 23). Cambridge, MA: Harvard University, Project Zero. (ERIC Document Reproduction Service No. ED 210 682).

Wang, Wei (2001), 'Internet Dependency and Psychosocial Maturity Among College Students', 55 Int'1 Journal of Human-Computer Studies 919. 
Wartella et al. (2003), The Role of Interactive Media in Children's Cognitive Development, pp. 461-479 in Valdivia, Angharad, N., (ed.), A Companion to Media Studies, Oxford, UK: Blackwell.

Webb, E. (1980),'Images Of Television: Some Reflections', Use of English, 32:1, pp. 10-17.

Williams, Ian (2007), 'Chinese Gamer Dies After 15-Day Session', VNUNet.com (Mar. 1, 2007), http://www.vnunet.com/vnunet/news/2184523/online-addict-games-himself.

Young, Kimberly (1997), 'What Makes the Internet Addictive: Potential Explanations for Internet Use', Paper presented at the 105th Annual Conference of the American Psychological Association, Chicago, IL.

Yee, Nick (2002), Ariadne - Understanding MMORPG Addition, NickYee.com (Oct. 2002), http://www.nickyee.com/hub/addiction/home.html.

(2004), The Daedalus Project: Addiction, NickYee.com (Jul. 9, 2004), http:// www.nickyee.com/daedalus/archives/000818.php.

Ying, Shen et al. (2006), 'The Death of a Young Online Game Player', EastSouthWestNorth.com (Mar. 4, 2006), http://www.zonaeuropa.com/20060304_1.htm.

Young, Kimberly (1996a), 'Internet Addiction: The Emergence of a New Clinical Disorder', 1 Cyberpsychology and Behavior 237, http://newmedia.cityu.edu.hk/COM5108/readings/ newdisorder.pdf.

Zimbardo, Philip \& Boyd, John (2008), The Time Paradox, New York: Free press (2008). 